Review Article

\title{
Outcome of yoga nidra practice on various mental health problems and general wellbeing: a review study
}

\author{
Kalamani Dhamodhini ${ }^{1}$, Muthappan Sendhilkumar ${ }^{2 *}$
}

${ }^{1}$ Government Yoga and Naturopathy College and hospital, Chennai, India
${ }^{2}$ Independent Siddha Researcher, Chennai, Tamil Nadu, India

Received: 22 October 2018

Revised: 29 November 2018

Accepted: 30 November 2018

\author{
*Correspondence: \\ Dr. Muthappan Sendhilkumar, \\ E-mail: drsendhil1986@gmail.com
}

Copyright: () the author(s), publisher and licensee Medip Academy. This is an open-access article distributed under the terms of the Creative Commons Attribution Non-Commercial License, which permits unrestricted non-commercial use, distribution, and reproduction in any medium, provided the original work is properly cited.

\begin{abstract}
Mental disorders comprise a wide range of mental health problems with different symptoms. The most of the mental health disorders can be successfully treated with proper treatment and care by health facilities. The yoga founders were great saints and sages from India. The great Yogis presented rational interpretation of their experiences of yoga and brought about a practical and scientifically sound method within every one's reach. Yoga nidra effectively provides impact on stress, anxiety levels, post-traumatic stress disorder (PTSD) symptoms like rage and anxiety and increased feelings of relaxation and peace after yoga nidra as a therapy.
\end{abstract}

Keywords: Yoga, Yoga nidra, Mental health, Depression

\section{INTRODUCTION}

Mental health is defined as a state of well-being in which every individual realizes his or her own potential, can cope with the normal stresses of life, can work productively and fruitfully, and makes a contribution to her or his community. WHO's comprehensive mental health action plan for 2013-2020 mentioned following four main objectives. The objectives focus on effective leadership and governance, comprehensive mental health for community, promotion, and prevention of mental health, use of IT systems and research on mental health. ${ }^{1,2}$

Mental disorders include broad range mental health problems. The most of the mental health disorders are successfully treated with proper treatment and care by health facilities if identified early as the advanced treatments are available now. The report also show that nearly quarter of population has the chance get any mental health problems in one lifetime. Globally, nearly 450 million mainly in developed and developing suffering from mental health disorders and lies in top in a table among the leading causes of ill-health and disability worldwide. $^{3,4}$ As per WHO report, the depression is ranked single largest contributor to global disability (7.5\% of all years lived with disability in 2015) followed by anxiety disorders (ranked 6th $(3.4 \%) .^{5}$

The overall prevalence for any mental morbidity was $13.7 \%$ in a lifetime. As per the Indian study, the small North East Indian state Manipur (19.9) top in the list and another North East Indian state Assam (8.1) in bottom of the list for lifetime prevalence. India accounts for nearly $18 \%$ of the world population and loss nearly $15 \%$ DALYs due to mental health problems. The burden of depression (DALYs) increased by $67 \%$ between 1990 and 2013 globally. ${ }^{\text {? }}$

Yoga originated in India several thousand years and played a vital role in keeping health of the people. The great saints, sadhus, Siddhars were found, practiced and spread all over the India. Now, yoga is universal in 
character and practiced all over the globe to improve the physical and mental health of people. The yoga practice and application is irrespective of culture, nationality, gender, age and physical condition. Even though the growing clinical research studies, and some reviews shows the use of yoga as therapeutic effects, there is still a lack of solid evidence regarding its clinical relevance for many symptoms and medical conditions. ${ }^{8}$

The many studies show that the yoga has huge impact on improving mental health and memory. The studies in older adults reveal that Yoga is helpful in preventing cognitive decline, focused attention and improve working memory performance. ${ }^{9,10}$ An 8-week meditation program resulted in improvements in neuropsychological function. Kirtan Kriya yoga intervention showed that effective in improving memory functions and functional connectivity-related to verbal, attention, and selfregulatory performance. ${ }^{11,12}$

Yoga nidra along with other advanced medical procedures has been potentially used in the management of many psychosomatic disorders such as menstrual irregulations, cancer, asthma, peptic ulcer. Yoga nidra is one such effective technique, not only for physical or mental relaxation but also for preparing the mind for yogic discipline. Many misunderstood that yoga nidra for sleep only. Apart from relaxation, the yoga nidra provides much more intense than ordinary sleep. Yoga nidra aims to focus the mind to achieve relaxation and increase wellness. Many research studies indicate that yoga nidra can be used as a therapeutic technique to cure psychological disorders like anxiety, hostility, insomnia etc, and psychosomatic diseases like asthma, coronary heart disease, cancer, and hypertension. ${ }^{13}$

\section{YOGA NIDRA}

Yoga nidra, also known as dynamic sleep, prompts the body to relax deeply while the mind remains inwardly alert.

\section{PROCEDURE}

To start yoga nidra practice, you begin by lying on the floor (face up) in yoga corpse pose or Shavasana. Then, based upon the guided meditation you're following, you're prompted to begin sensing the body and breathing in specific ways to incite a relaxation response in you. Yoga nidra works by gently guiding you through four main stages of brain wave activity - beta, alpha, theta, and delta. In the end, the goal is to achieve a "hypnagogic state" - the state between wakefulness and sleep. It's that mysterious time just before you fall asleep when the body rests while the mind is still reasonably clear. Conscious thought then blends with dreams, and a trippy certainty sets in.

\section{YOGA NIDRA INTERVENTION}

The yoga nidra procedure developed from Munger, Bihar by Swami Satyananda Saraswati, School of Yoga in India. A study conducted in Department of Physiology King George's Medical University, Lucknow, Uttar Pradesh for first three months was a big breakthrough for yoga nidra. Yoga instructor was selected by an expert panel for this study. The yoga classes for the patients consisted of 30 to 35 minute /day session, five days in a week where yoga nidra taught by a trained yoga therapist. Thereafter the patients were advised to continue the same at their homes for next three months; the yoga lasted for 6 months in the intervention group. ${ }^{14}$ Yoga nidra can be a successful therapy to overcome the psychiatric morbidity associated with menstrual irregularities and other psychosomatic disorders. ${ }^{15}$

\section{BENEFITS OF A YOGA NIDRA}

The researchers acknowledged the positive impact of yoga nidra on mental health problems. A study conducted on 100 women with depression and anxiety linked to menstruation benefited from yoga nidra therapy. ${ }^{16}$ Yoga nidra diminished stress and anxiety levels significantly 80 college students Military combat veterans reported alleviation of post-traumatic stress disorder (PTSD) symptoms like rage and anxiety and increased feelings of relaxation and peace after yoga nidra as a therapy. ${ }^{13,17,18}$

The study revealed significant improvement in anxiety scores after six months of intervention with Yoga Nidra in intervention group in comparison to control group. Previous studies have also shown significant reduction in the quality anxiety scores following meditation and breathing exercises. ${ }^{19}$ There is an increased response of hypothalamus and heightened sympathetic activity during anxiety, yoga nidra appears to regulate a hypothalamus, in a way resulting in decreased sympathetic (excitatory) nervous activity and increased parasympathetic (inhibitory) function. ${ }^{20,21}$ In the intervention group which practiced yoga nidra for six months, there was significant decrease in their degree of depressive symptoms (according to the psychological general wellbeing Index). ${ }^{22}$

Yoga Nidra gives some solid evidence for psychosomatic problems. It is cost-effective and easy to implement. The evidence from two RCTs done in different place with different conditions that yoga nidra may have positive effects in reducing psychological problems in women with menstrual disorders. ${ }^{22,23}$ The findings suggest that patients with menstrual irregularities having psychological problems improved significantly in the areas of their wellbeing, anxiety and depression by learning and applying a program based on yoga nidra. ${ }^{24}$ The case group also show significant decreased anxiety. Previous studies have also shown that employing yoga interventions for other conditions (cancer survivors, selfreported emotional distress) results in beneficial effects 
for depression and mood, as well as anxiety and physical wellbeing. ${ }^{25-27}$

\section{CONCLUSION}

Most studies described beneficial effects in favour of the yoga interventions, particularly when compared with passive controls (i.e., examination anxiety), but also compared with active controls such as relaxation response or compared to standard drugs. The results show that there was a significant improvement in positive wellbeing, general health and vitality in the case group. Yoga nidra is believed to balance psychic and vital energies within the psychic channels (nadis) of the energy framework underlying the physical body. Free flow of these energies is considered to be the basis of optimal physical and mental health.

\section{Funding: No funding sources Conflict of interest: None declared \\ Ethical approval: Not required}

\section{REFERENCES}

1. WHO. Mental health: a state of well-being. WHO. Available at: http://www.who.int/features/factfiles/ mental_health/en/. Accessed on 18 July 2018.

2. WHO Comprehensive mental health action plan 2013-2020. WHO. Available at: http://www.who. int/entity/mental_health/action_plan_2013/en/index. html. Accessed on 18 July 2018.

3. WHO. Mental disorders. WHO. Available at: http://www.who.int/mental_health/management/en/ Accessed on 18 July 2018.

4. WHO. Mental disorders affect one in four people. WHO. Available at: http://www.who.int/whr/2001/ media_centre/press_release/en/. Accessed on 18 July 2018.

5. WHO-MSD-MER-2017.2-eng.pdf. Available from: http://apps.who.int/iris/bitstream/handle/10665/2546 10/WHO-MSD-MER-2017.2-eng.pdf;jsessionid= C8D15367E42792D81F65E556A2B0206A?sequen ce $=1$. Accessed on 18 July 2018.

6. Murthy RS. National mental health survey of India 2015-2016. Indian Journal of Psychiatry. 2017;59(1):21.

7. Depression_in_india.pdf. Available at: http://www.searo.who.int/india/depression_in_india. pdf. Accessed on 18 July 2018.

8. Yoga Ministry of AYUSH, GOI. Available at: http://ayush.gov.in/about-the-systems/yoga. Accessed on 18 July 2018.

9. Gothe NP, Kramer AF, McAuley E. The effects of an 8-week Hatha yoga intervention on executive function in older adults. J Gerontol A Biol Sci Med Sci. 2014;69(9):1109-16.

10. Gothe NP, Keswani RK, McAuley E. Yoga practice improves executive function by attenuating stress levels. Biol Psychol. 2016;121(Pt A):109-16.
11. Newberg AB, Wintering N, Khalsa DS, Roggenkamp H, Waldman MR. Meditation effects on cognitive function and cerebral blood flow in subjects with memory loss: a preliminary study. J Alzheimers Dis. 2010;20(2):517-26.

12. Eyre HA, Acevedo B, Yang H, Siddarth P, Van Dyk $\mathrm{K}$, Ercoli L, et al. Changes in Neural Connectivity and Memory Following a Yoga Intervention for Older Adults: A Pilot Study. J Alzheimers Dis. 2016;52(2):673-84.

13. Stankovic L. Transforming trauma: a qualitative feasibility study of integrative restoration (iRest) yoga Nidra on combat-related post-traumatic stress disorder. Int J Yoga Therap. 2011;(21):23-37.

14. Rani K, Tiwari SC, Kumar S, Singh U, Prakash J, Srivastava N. Psycho-Biological Changes with Add on Yoga Nidra in Patients with Menstrual Disorders: a Randomized Clinical Trial. J Caring Sci. 2016;5(1):1-9.

15. Eppley KR, Abrams AI, Shear J. Differential effects of relaxation techniques on trait anxiety: a metaanalysis. J Clin Psychol. 1989 Nov;45(6):957-74.

16. Rani K, Tiwari S, Singh U, Singh I, Srivastava N. Yoga Nidra as a complementary treatment of anxiety and depressive symptoms in patients with menstrual disorder. Int J Yoga. 2012;5(1):52-6.

17. Kumar K. A study on the impact on stress and anxiety through Yoga nidra. 2008;7(3):4.

18. Pence PG, Katz LS, Huffman C, Cojucar G. Delivering Integrative Restoration-Yoga Nidra Meditation (iRest®) to Women with Sexual Trauma at a Veteran's Medical Center: A Pilot Study. Int J Yoga Therap. 2014;24:53-62.

19. Brown RP, Gerbarg PL. Sudarshan Kriya yogic breathing in the treatment of stress, anxiety, and depression: part I-neurophysiologic model. J Altern Complement Med. 2005;11(1):189-201.

20. Stoudenmire J. A comparison of muscle relaxation training and music in the reduction of state and trait anxiety. J Clin Psychol. 1975;31(3):490-2.

21. Janakiramaiah N, Gangadhar BN, Naga Venkatesha Murthy PJ, Harish MG, Subbakrishna DK, Vedamurthachar A. Antidepressant efficacy of Sudarshan Kriya Yoga (SKY) in melancholia: a randomized comparison with electroconvulsive therapy (ECT) and imipramine. J Affect Disord. 2000;57(1-3):255-9.

22. Kim SD. Psychological effects of yoga nidra in women with menstrual disorders: A systematic review of randomized controlled trials. Complement Ther Clin Pract. 2017;28:4-8.

23. Rani K, Tiwari SC, Singh U, Agrawal GG, Srivastava N. Six-month trial of Yoga Nidra in menstrual disorder patients: Effects on somatoform symptoms. Ind Psychiatry J. 2011;20(2):97-102.

24. Rani K, Tiwari S, Singh U, Agrawal G, Ghildiyal A, Srivastava N. Impact of Yoga Nidra on psychological general wellbeing in patients with menstrual irregularities: A randomized controlled trial. Int J Yoga. 2011;4(1):20-5. 
25. Ray US, Mukhopadhyaya S, Purkayastha SS, Asnani V, Tomer OS, Prashad R, et al. Effect of yogic exercises on physical and mental health of young fellowship course trainees. Indian J Physiol Pharmacol. 2001;45(1):37-53.

26. Bower JE, Woolery A, Sternlieb B, Garet D. Yoga for cancer patients and survivors. Cancer Control. 2005;12(3):165-71.

27. Lavey R, Sherman T, Mueser KT, Osborne DD, Currier M, Wolfe R. The effects of yoga on mood in psychiatric inpatients. Psychiatr Rehabil J. 2005;28(4):399-402.

Cite this article as: Dhamodhini K, Sendhilkumar M. Outcome of yoga nidra practice on various mental health problems and general wellbeing: a review study. Int J Community Med Public Health 2019;6:446-9. 